\title{
Natural organic matter removal by ion exchange at different positions in the drinking water treatment lane
}

\author{
A. Grefte ${ }^{1}$, M. Dignum ${ }^{2}$, E. R. Cornelissen ${ }^{3}$, and L. C. Rietveld ${ }^{1}$ \\ ${ }^{1}$ Delft University of Technology, Faculty of Civil Engineering, P.O. Box 5048, \\ 2600 GA Delft, The Netherlands \\ ${ }^{2}$ Waternet, P.O. Box 94370, 1090 GJ Amsterdam, The Netherlands \\ ${ }^{3}$ KWR Watercycle Research Institute, P.O. Box 1072, 3430 BB Nieuwegein, The Netherlands \\ Correspondence to: A. Grefte (a.grefte@tudelft.nl)
}

\begin{abstract}
Received: 5 June 2012 - Published in Drink. Water Eng. Sci. Discuss.: 12 July 2012
\end{abstract}
Revised: 5 December 2012 - Accepted: 21 December 2012 - Published: 11 January 2013

\begin{abstract}
To guarantee a good water quality at the customers tap, natural organic matter (NOM) should be (partly) removed during drinking water treatment. The objective of this research was to improve the biological stability of the produced water by incorporating anion exchange (IEX) for NOM removal. Different placement positions of IEX in the treatment lane (IEX positioned before coagulation, before ozonation or after slow sand filtration) and two IEX configurations (MIEX ${ }^{\circledR}$ and fluidized IEX (FIX)) were compared on water quality as well as costs. For this purpose the pre-treatment plant at Loenderveen and production plant Weesperkarspel of Waternet were used as a case study. Both, MIEX ${ }^{\circledR}$ and FIX were able to remove NOM (mainly the HS fraction) to a high extent. NOM removal can be done efficiently before ozonation and after slow sand filtration. The biological stability, in terms of assimilable organic carbon, biofilm formation rate and dissolved organic carbon, was improved by incorporating IEX for NOM removal. The operational costs were assumed to be directly dependent of the NOM removal rate and determined the difference between the IEX positions. The total costs for IEX for the three positions were approximately equal $\left(0.0631 € \mathrm{~m}^{-3}\right)$, however the savings on following treatment processes caused a cost reduction for the IEX positions before coagulation and before ozonation compared to IEX positioned after slow sand filtration. IEX positioned before ozonation was most cost effective and improved the biological stability of the treated water.
\end{abstract}

\section{Introduction}

Drinking water treatment consists of different steps, depending on the quality of the source water. The presence of natural organic matter (NOM) can cause problems in the treatment, as well as in the distribution of drinking water. NOM can be a source for regrowth in the distribution system, thus decreasing the biological stability of the drinking water (van der Kooij et al., 1982). When the source water contains high NOM concentrations, this should be removed to a high extent during drinking water treatment. NOM can be removed by coagulation, activated carbon filtration, membrane filtration and anion exchange (IEX).

NOM in surface water can be removed by IEX, because the main part of NOM, humic, fulvic and organic acids, is negatively charged (Bolto et al., 2002; Cornelissen et al., 2008). IEX is a promising method for NOM removal, because empty bed contact times can be small and run times of IEX columns can be up to several weeks (van der Helm et al., 2009). IEX is relatively cost effective, easy to operate and a compact installation can be used due to the short contact times (Cornelissen et al., 2009). The efficiency of NOM removal by IEX depends on i.a. NOM concentration, NOM composition, type of IEX resin, empty bed contact time and configuration of the IEX installation. NOM fractions of low and high molecular weight (MW) are known to be removed by IEX (Croue et al., 1999; Bolto et al., 2002; Allpike et al., 2005; Boyer and Singer, 2005; Humbert et al., 2005). Weak base resins do not remove NOM as efficient as strong base 
resins (Croue et al., 1999) and the bead size of the resin, water retention, capacity and functional groups of the resin (Cornelissen et al., 2008) will also influence the removal efficiency. IEX can be operated as a packed bed or in a fluidized mode, like Magnetic IEX (MIEX ${ }^{\circledR}$ ) (Drikas et al., 2002), Fluidized IEX (FIX) (Cornelissen et al., 2009) or suspended IEX (SIX) (Galjaard et al., 2011). When the resin is exhausted, a $10 \%$ sodium chloride solution can be used for regeneration of the resin; the NOM ions are exchanged to chloride ions. The residual or waste of IEX regeneration consists of water, salt $(\mathrm{NaCl})$ and humic substances. The waste can be discharged to the sewer or directly to the waste water treatment plant. However, humic substances are not readily biodegradable and will substantially remain in the effluent of the waste water treatment. Additionally, high salt solutions could give problems in waste water treatment. To limit the residual, the brine can be reused (Schippers et al., 2004). Separating the salt from the humic substances is possible by membrane filtration. In that way the salt can be reused and only the higher concentration of humic substances is discharged to the sewer (Schippers et al., 2004; Kabsch-Korbutowicz et al., 2011).

The objective of this research is to improve the drinking water quality, including biological stability, by incorporating IEX for NOM removal. Different placement positions of IEX in the treatment lane were compared on water quality as well as costs. For this purpose the pre-treatment plant at Loenderveen and production plant Weesperkarspel (WPK) of Waternet, the water cycle company of Amsterdam (NL) and surrounding areas, were used as a case study. The treatment lane consists of coagulation, lake retention, filtration, ozonation, softening, biological activated carbon (BAC) filtration and slow sand filtration (SSF). Assimilable organic carbon (AOC) values below $10 \mu \mathrm{gCL}^{-1}$ have been derived as a reference value for biostable drinking water during distribution (van der Kooij, 1992), whereas current AOC concentrations are approximately $20 \mu \mathrm{gCL}^{-1}$ (Baghoth et al., 2009) in the finished water. The biofilm monitor was developed as a tool to determine the biofilm formation characteristics of drinking water (van der Kooij, 1995). A biofilm formation rate (BFR) below $10 \mathrm{pg}$ ATP $\mathrm{cm}^{-2} \mathrm{day}^{-1}$ reduces the risk of exceeding the Dutch guideline value for Aeromonas in the distribution system to less than $20 \%$ (van der Kooij et al., 1999). Thus, biologically stable water was defined in this study as having an AOC concentration lower than $10 \mu \mathrm{gCL}^{-1}$ and a BFR below $10 \mathrm{pg}$ ATP $\mathrm{cm}^{-2} \mathrm{day}^{-1}$. By removing humic substances by IEX before ozonation it is expected that ozonation will form less biodegradable NOM than without IEX. IEX positioned after slow sand filtration is expected to lower the AOC and BFR values by itself. In both cases, a reduction in dissolved organic carbon (DOC) concentration in the finished water from approximately 2.7 to $1 \mathrm{mgCL}^{-1}$ was aimed for.

First, pilot experiments were conducted with IEX positioned at two locations: (1) halfway the treatment lane, before ozonation and (2) after the treatment lane, before dis- tribution. Experiments were conducted by two IEX configurations, namely FIX and MIEX ${ }^{\circledR}$. Both IEX pilots were compared on NOM removal by LC-OCD characterization. Second, the effect on the biological stability of the produced water was researched for IEX at these two positions. Third, based on the results three possible positions in the treatment lane (IEX before coagulation was added) were compared on costs per cubic meter of treated water after the complete treatment lane.

\section{Materials and methods}

\subsection{Treatment scheme}

For this investigation pre-treatment plant Loenderveen and production plant WPK were used as a case study. The production of WPK is approximately $30 \mathrm{Mm}^{3}$ per year. At the pre-treatment plant surface water from the Bethune polder is treated by coagulation and sedimentation, followed by natural self-purification in a lake reservoir and rapid sand filtration. The pre-treatment plant partially removes suspended solids, phosphate, heavy metals, and pathogenic micro-organisms. It converts ammonium into nitrate and provides smoothing of peak loads. The pre-treated water is pumped to the production plant at WPK. There the water is treated by ozonation for disinfection, the hardness is reduced by pellet softening followed by removal of organic compounds in BAC filtration. As a final treatment step, the water passes through slow sand filters for the removal of pathogenic micro-organisms and for lowering the AOC concentration. The experiments were conducted at WPK pilot plant, owned and operated by Waternet. The pilot plant of WPK consists of 2 lanes of the same treatment processes and with similar contact times as in the full-scale treatment plant on a scale of approximately $1: 200$ compared to the full-scale treatment plant. The maximum flow in the pilot plant was $7 \mathrm{~m}^{3} \mathrm{~h}^{-1}$ for each lane. The pilot plant was extended with a MIEX ${ }^{\circledR}$ pilot and a FIX pilot in one of the lanes. The MIEX ${ }^{\circledR}$ pilot used in this experiment is the high rate configuration. In this configuration, raw water fed to the base of the reactor vessel is mixed with the MIEX ${ }^{\circledR}$ resin, causing the ion exchange process to occur in a fluidized bed. In the fluidized bed the magnetic particles are attracted to each other to form large agglomerates that form a stable resin suspension. An agitator operating at low velocity keeps the resin/water suspension uniformly mixed. A small stream of resin is withdrawn from the reactor vessel, regenerated twice a week with a $12 \% \mathrm{NaCl}$ solution and returned to maintain the ion exchange capacity of the process. A series of plates (or tube settlers) at the top of the reactor vessel separate the resin from the water and treated effluent overflows (OricaWatercare, n.d.). To prevent resin carry-over a magnetic capture device was built in the MIEX $^{\circledR}$ pilot plant. Additional, the MIEX $^{\circledR}$ pilot plant was extended by a filter bag with pore size of $100 \mu \mathrm{m}$ and a settling tank. The influent flow rate 
of the MIEX ${ }^{\circledR}$ pilot plant was $300 \mathrm{~L} \mathrm{~h}^{-1}$. The contact time was $3 \mathrm{~min}$. The fluidized bed volume in the contacter was $15 \mathrm{~L}$. The volume ratio of resin to water was $210 \mathrm{mlL}^{-1}$. Fresh resin was pumped into the contacter with a flow of $12 \mathrm{mlmin}^{-1}$. The resin service was 1984 bed volumes. The MIEX $^{\circledR}$ pilot was placed before ozonation (for 4 weeks) and in one of the lanes after SSF (for 4 months).

The FIX pilot, as described by Cornelissen et al. (2009), was positioned prior to ozonation (for 4 months). Three FIX columns were operated in parallel with a flow of $4 \mathrm{~m}^{3} \mathrm{~h}^{-1}$ each and contained Lewatit VP OC 1071 type resin, which is a strong-base gel resin with an acrylic (type 1) structure. This resin was the best performing resin for WPK feed water, according to a selection study on lab scale (Cornelissen et al., 2008). The height of the ion exchange bed was approximately $0.5 \mathrm{~m}$, when fluidized it was approximately $1 \mathrm{~m}$. The surface area was $0.3 \mathrm{~m}^{2}$, each column was filled with $150 \mathrm{~L}$ of resin and the empty bed contact time was approximately $2.3 \mathrm{~min}$. After a run time of 15000 bed volumes the resin was regenerated with a $10 \% \mathrm{NaCl}$ solution.

\subsection{Analyses}

The water samples were analyzed for general physicochemical characteristics such as DOC, ultra violet absorbance at $254 \mathrm{~nm}$ (UV254), $\mathrm{pH}$ and temperature, which were determined using standard procedures following Eaton et al. (2005). Liquid chromatography with organic carbon detection (LC-OCD) with ultra violet (UV) and online organic carbon (OC) detection (UVD and OCD, respectively) was used for NOM characterization (Huber et al., 2011). Water samples were analyzed after filtration through $0.45 \mu \mathrm{m}$ filters. LC-OCD separates chromatographable organic carbon (CDOC) into fractions of different molecular weights. The non-chromatographable organic carbon, which remains on the column, is referred to as hydrophobic organic carbon (HOC). CDOC is fractionated into (a) biopolymers (BP), which is a non-ionic, hydrophilic fraction with a high molecular weight $\left(\geq 10000 \mathrm{~g} \mathrm{~mol}^{-1}\right)$; (b) humic substances (HS) (450-1000 $\left.\mathrm{g} \mathrm{mol}^{-1}\right)$, that are a heterogeneous fraction of similar chemical composition but varying molecular size and aromaticity, (c) building blocks (BB), a fraction that consists of breakdown products of HS, which is HS-like material of lower molecular weight $\left(300-450 \mathrm{~g} \mathrm{~mol}^{-1}\right)$; (d) lowmolecular weight (LMW) acids $\leq 350 \mathrm{~g} \mathrm{~mol}^{-1}$ ) and (e) lowmolecular weight neutrals, a fraction with a low molecular weight and a low ion density and the fraction is hydrophilic to amphiphilic (Huber and Frimmel, 1996; Huber, 2005; Huber et al., 2011). For data acquisition and data processing of the LC-OCD data a customized software program (FIFFIKUS, DOC-LABOR, Germany) was used. This program integrates the different peaks to determine the concentration of different organic fractions. In Huber et al. (2011) it was explained that a small portion of HS, which is called the LMW-HS, is trapped in the LMW-acids zone. To distinguish between
LMW-acids and LMW-HS the UV/OC ratio of HS is used to determine the concentration of LMW-HS, by assuming the same UV/OC ratio for LMW-HS as for HS. The concentration of LMW-acids is calculated by subtracting the concentration of LMW-HS from the total surface of the peak LMWHS and LMW-acids. In this research the fractions were determined without correction for LMW-HS.

The change in relative signal response from the chromatograms of LC-OCD before and after treatment, is called a differential chromatogram. With a differential chromatogram small qualitative changes in NOM fractions are visualized. A similar differential spectrum analysis was used by Korshin et al. (1999) for light absorption spectra.

The aromaticity per DOC is determined by the specific UV254 absorbance (SUVA = UV254/DOC). SUVA $\geq$ $4 \mathrm{Lmg} \mathrm{C}^{-1} \mathrm{~m}^{-1}$ indicates that mainly hydrophobic and especially aromatic material or humic substances are present, while SUVA $\leq 2 \mathrm{Lmg} \mathrm{C}^{-1} \mathrm{~m}^{-1}$ represents hydrophilic material or non-humic material (Edzwald et al., 1985).

The concentration of AOC was determined, with growth measurements in water samples of $600 \mathrm{ml}$. Two pure cultures of bacteria were used by applying the simultaneous incubation of strains Pseudomonas fluorescens (strain P17), which is capable of utilizing a wide range of low-molecularweight compounds at very low concentrations and Spirillum sp. (strain NOX), which utilizes only carboxylic acids. The AOC concentration was calculated from the obtained maximum colony counts of these strains, using their yield values for acetate (van der Kooij et al., 1982; van der Kooij and Hijnen, 1984; van der Kooij, 1992). AOC was measured in duplicate and the average value was reported.

Biofilm monitors were used to determine the biofilm formation characteristics of drinking water (van der Kooij, 1995). The biofilm monitor consists of a vertically-placed glass column containing glass cylinders on top of each other. Water flows through the column with a flow of $270 \mathrm{Lh}^{-1}$. Every other week two cylinders were collected. The biomass attached to these cylinders was released by sonication and the ATP concentration was determined (van der Kooij et al., 2003).

\subsection{Cost comparison and environmental impact}

A technical-economical assessment was made using IEX in the WPK treatment. In Table 1 the DOC concentrations after every treatment step, in normal operation (without IEX treatment), are given (Baghoth et al., 2009). In order to obtain a DOC concentration of $1 \mathrm{mgCL}^{-1}$ after treatment, three positions were selected for NOM removal by IEX, namely before coagulation, before ozonation and as polishing step after SSF. For all positions the required DOC concentrations after IEX are given in Table 1. It was assumed that after IEX subsequent treatment processes remove DOC at the same rate as without IEX pre-treatment (coagulation $21 \%$, reservoir $8 \%$, 
Table 1. The expected variation of dissolved organic carbon (DOC) across the treatment train (based on Baghoth et al., 2009).

\begin{tabular}{lcccc}
\hline DOC concentration $\left(\mathrm{mg} \mathrm{C} \mathrm{L}^{-1}\right)$ & Actual & $\begin{array}{c}\text { Before } \\
\text { coagulation }\end{array}$ & $\begin{array}{c}\text { Before } \\
\text { ozonation }\end{array}$ & $\begin{array}{c}\text { After } \\
\text { SSF }\end{array}$ \\
\hline Raw surface water & 9.0 & 9.0 & 9.0 & 9.0 \\
IEX effluent & - & 3.5 & - & - \\
Coagulation effluent & 7.1 & 2.7 & 7.1 & 7.1 \\
Surface reservoir effluent & 6.5 & 2.5 & 6.5 & 6.5 \\
Rapid sand filtration effluent & 6.0 & 2.2 & 6.0 & 6.0 \\
IEX effluent & - & - & 2.2 & - \\
Ozonation effluent & 5.7 & 2.1 & 2.1 & 5.7 \\
Pellet softening effluent & 5.4 & 2.0 & 2.0 & 5.4 \\
Biological activated carbon & 3.0 & 1.2 & 1.2 & 3.0 \\
filter effluent & & & & \\
IEX effluent & - & - & - & 1.0 \\
Treated water & 2.7 & 1.0 & 1.0 & 1.0 \\
\hline
\end{tabular}

rapid sand filtration $8 \%$, ozonation $5 \%$, pellet softening $5 \%$, biological activated carbon filtration $44 \%$ and SSF $10 \%$ ).

A preliminary design for the IEX plant, independent of the location, is given in Table 2. The costs of an IEX installation consists of investment costs, capital costs, maintenance costs, chemicals, disposal costs, energy and staff. Except for chemicals and disposal costs, all costs were considered to be independent of the position of IEX in the treatment lane as well as independent of the removal rate and are given in Table 3. To compare the different positions of IEX in the treatment lane the breakthrough curve of one FIX pilot plant column, operated on WPK feed water, was taken as a starting point (Fig. 1). The design is based on 22 columns, see Table 2 . When the filter run time of every individual column is $13500 \mathrm{BV}$, then every day one column is regenerated. The effluent DOC concentration of all the columns is the average DOC concentration of the effluent concentrations of the individual columns. The column just regenerated produces water with a lower DOC concentration than the column that runs already for 20 days. For a filter run time of $13500 \mathrm{BV}$ the average removal will be $60 \%$, so $40 \%$ of the influent DOC will be found in the effluent. The average DOC concentration was calculated for filter run times of $3000 \mathrm{BV}$, $6000 \mathrm{BV}, 13500 \mathrm{BV}, 25000 \mathrm{BV}$ and $50000 \mathrm{BV}$ and interpolated for other filter run times as is shown in Fig. 1. Different NOM removal rates can be obtained by applying different filter run times for 22 columns and thus different regeneration frequencies. The calculations were done with a contact time of $2.3 \mathrm{~min}$ for all configurations. The NOM removal rate influences the operational costs, particularly costs for salt consumption and waste disposal. The cost for the discharge of waste were determined by the waste load expressed in pollution equivalents (PE) (van Lier, 2011). The PE is determined by: $\mathrm{PE}=\frac{Q}{1000} \cdot\left(\frac{\mathrm{COD}+4 \cdot K j N}{54.8}\right)$ in which $Q=$ flow $\left(\mathrm{m}^{3} \mathrm{yr}^{-1}\right), \mathrm{COD}$ $($ chemical oxygen demand $)=3 \cdot \mathrm{DOC}\left(\mathrm{mg} \mathrm{L}^{-1}\right)($ DowChemicalCompany, 2011), $\mathrm{KjN}$ (Kjeldahl nitrogen) was assumed to be negligible. The costs per PE are approximately $50 €$. The waste is transported by tanker trucks with a volume of $10 \mathrm{~m}^{3}$.
Table 2. Design of IEX treatment.

\begin{tabular}{ll}
\hline Total production & $30 \mathrm{Mm}^{3} \mathrm{yr}^{-1}$ \\
Empty bed contact time & $2.3 \mathrm{~min}$ \\
Reactor & 22 columns \\
Total bed volume & $190 \mathrm{~m}^{3}$ resin \\
Bed volume per column & $8.6 \mathrm{~m}^{3} \mathrm{resin}$ \\
Flow per column & $220 \mathrm{~m}^{3} \mathrm{~h}^{-1}$ \\
Salt solution & $10 \% \mathrm{NaCl}$ \\
Regeneration & $1.8 \mathrm{BV}$ brine \\
Rinse & $2.4 \mathrm{BV}$ water \\
\hline
\end{tabular}

The distance to the nearest waste water treatment plant was assumed to be $15 \mathrm{~km}$. A tanker truck with driver costs approximately $70 € \mathrm{~h}^{-1}$ and it takes $2 \mathrm{~h}$ per tanker truck to be filled, to drive and to discharge the water. With these assumptions, the costs for transportation are $14 € \mathrm{~m}^{-3}$. The costs for salt are $0.1 € \mathrm{~kg}^{-1}$.

The environmental and financial impact of drinking water production plant Weesperkarspel and its pre-treatment plant Loenderveen were determined by Barrios et al. (2008). For calculating cost savings of treatment processes following IEX and for determining the environmental impact of IEX numbers were taken from their study. Barrios et al. (2008) calculated costs for the different treatment steps for 2002, for this research actual costs (2012) were calculated with an inflation of $1.7 \%$ per year.

\section{Results and discussion}

\subsection{NOM removal by MIEX ${ }^{\circledR}$ and FIX}

The MIEX ${ }^{\circledR}$ pilot positioned before ozonation caused an average DOC concentration decrease from 5.7 to $2.5 \mathrm{mg} \mathrm{CL}^{-1}$. This is a decrease of $56.1 \%$ and a removal of $3.2 \mathrm{mgCL}^{-1}$. FIX removed DOC on average from 5.9 to $3.0 \mathrm{mgCL}^{-1}$ which is a removal of $2.9 \mathrm{mgCL}^{-1}$ or $49.2 \%$. The removal of DOC by MIEX ${ }^{\circledR}$ after SSF was on average $57.7 \%$ or $2.2 \mathrm{mgCL}^{-1}$ (3.8 to $\left.1.6 \mathrm{mgCL}^{-1}\right)$. The removal rate at both locations was comparable, however, the absolute removal was higher for water before ozonation. This can be explained by the fact that ion exchange from the water to the resin is based on equilibrium reactions, and a higher DOC concentration results in a larger driving force.

The SUVA was lowered by both IEX treatment systems before ozonation from 2.6 to $1.6 \mathrm{~L} \mathrm{mg} \mathrm{C}^{-1} \mathrm{~m}^{-1}(38.4 \%)$, after SSF the decrease was from 1.5 to $0.9 \mathrm{~L} \mathrm{mg} \mathrm{C}^{-1} \mathrm{~m}^{-1}(40.0 \%)$, which is comparable to the decrease before ozonation. The decrease in SUVA means that the aromaticity of the water decreased (Edzwald et al., 1985); NOM with double bonds was removed to a higher extent than NOM with single bonds, and preferentially the higher molecular weight NOM was removed. In Fig. 2 the (differential) OCD chromatograms of the different water types are given. This figure shows that 
Table 3. Total fixed costs.

\begin{tabular}{lrllr}
\hline Subject & Amount & Unit & & Costs $\left(€ \mathrm{yr}^{-1}\right)$ \\
\hline Depreciation & & & Interest (Linear) $5 \%$ & 702000 \\
\hline Civil construction & 1750000 & $€$ & $30 \mathrm{yr}$ & 102000 \\
Installation construction & 6600000 & $€$ & $20 \mathrm{yr}$ & 495000 \\
Engineering construction & 1000000 & $€$ & $30 \mathrm{yr}$ & 58000 \\
Intern process construction & 800000 & $€$ & $30 \mathrm{yr}$ & 47000 \\
\hline Maintenance & & & & 207000 \\
\hline Civil & 7750000 & $€$ & $0.5 \%$ & 9000 \\
Installation & 6600000 & $€$ & $3 \%$ & 198000 \\
\hline Chemicals & & & & 220000 \\
\hline Resin-Lewatit VP OC 1071 & 40000 & $\mathrm{~L} \mathrm{yr}{ }^{-1}$ & $5.50 € \mathrm{~L}^{-1}$ & 220000 \\
\hline Energy & 900000 & $\mathrm{kWh} \mathrm{yr}{ }^{-1}$ & $0.09 € \mathrm{kWh}^{-1}$ & 81000 \\
\hline Staff & 0.25 & $\mathrm{FTE}$ & $55000 € \mathrm{yr}^{-1} \mathrm{FTE}^{-1}$ & 14000 \\
\hline Total fixed costs & & & & 1224000 \\
\hline
\end{tabular}

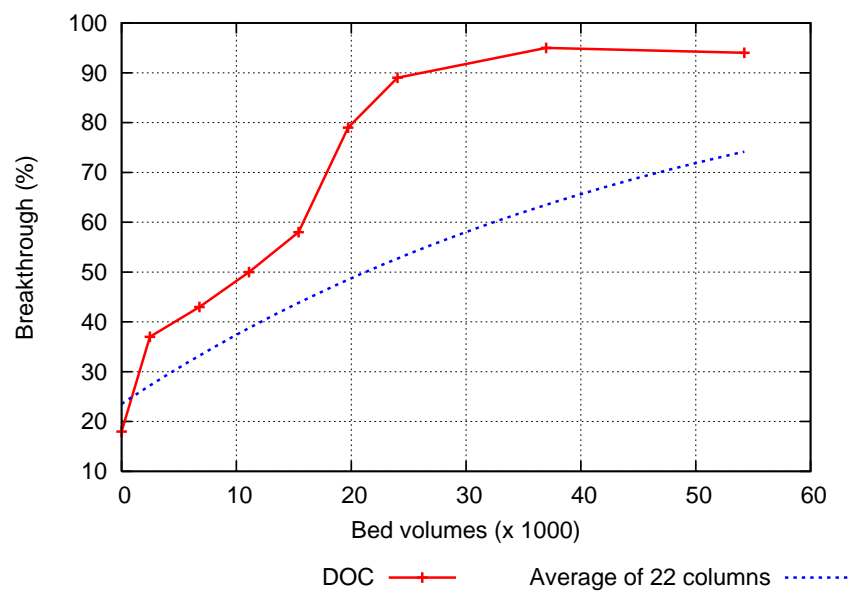

Figure 1. Breakthrough of one FIX column (positioned before ozonation in the WPK treatment plant) and the average of 22 columns for a certain filter run time (x-axis).

specifically the HS were removed from the water, independent of the water source. It also shows that MIEX ${ }^{\circledR}$ removed more of the lower MW NOM and FIX removed more of the HMW-HS. In Fig. 3 the concentrations of the different fractions are given. Although the decrease of the different fractions is higher for water before ozonation, the removal rates are of the same order of magnitude for both water types.

Overall, MIEX ${ }^{\circledR}$ showed a higher removal of NOM (fractions) than FIX. Possible explanations will be the longer contact time of the MIEX $^{\circledR}$ resin compared to the FIX ( 3 min for MIEX ${ }^{\circledR}$ and 2.3 min for FIX), the smaller resin beads (approximately $150 \mu \mathrm{m}$ ) for the MIEX ${ }^{\circledR}$ resin (Drikas et al., 2002) in comparison to the bead size of $0.4-1.6 \mathrm{~mm}$ for
Lewatit VP OC 1071 (Lewatit, n.d.) or the different operation conditions (the MIEX ${ }^{\circledR}$ pilot was a continuous process in one column, while every week one FIX column was regenerated and the effluent of three FIX columns were mixed). Figure $3 b$ showed an increase in BP after FIX treatment and an increase in LMW-acids after MIEX treatment at the end of the treatment lane, however the concentrations of both fractions are very low, and the increase rate will not be significant.

\subsection{Biological stability}

The AOC concentration in the water before ozonation was approximately $7 \mu \mathrm{gCL}^{-1}$. After FIX the concentration was lowered to approximately $3.5 \mu \mathrm{gCL}^{-1}$, a reduction of $50 \%$. By extending the treatment lane with FIX columns before ozonation, the ozonation formed less AOC than without FIX treatment $\left(54.5 \mu \mathrm{gCL} \mathrm{CL}^{-1}\right.$ instead of $\left.115.8 \mu \mathrm{g} \mathrm{CL}^{-1}\right)$, see Fig. 4. Because of this lower AOC concentration after ozonation, the AOC concentration after SSF was lower as well $\left(14.3 \mu \mathrm{gCL}^{-1}\right.$ instead of $\left.38.1 \mu \mathrm{gCL}^{-1}\right)$. By extending the treatment lane with $\mathrm{MIEX}^{\circledR}$ at the end of the treatment, the AOC concentration was decreased from 38.1 to $13.6 \mu \mathrm{g} \mathrm{CL}^{-1}$. Removing approximately $50 \%$ of DOC concentration before ozonation or $58 \%$ of DOC concentration after SSF resulted in the same AOC concentration after treatment.

The BFR of the water after SSF (before the MIEX ${ }^{\circledR}$ pilot) was $6.6 \mathrm{pg} \mathrm{ATP} \mathrm{cm}^{-2} \mathrm{day}^{-1}$. Immediately after starting up the experiment the ATP values for determining the BFR were much higher after the MIEX $^{\circledR}$ pilot than after SFF $\left(200 \mathrm{pg} \mathrm{ATP}^{-2}\right.$ versus $6.6 \mathrm{pg} \mathrm{ATP}^{-2}$ ). The ATP values after MIEX ${ }^{\circledR}$ treatment increased from $200 \mathrm{pg} \mathrm{ATP}^{-2}$ to $500 \mathrm{pg} \mathrm{ATP} \mathrm{cm}^{-2}$ and varied for the rest of the experimental 

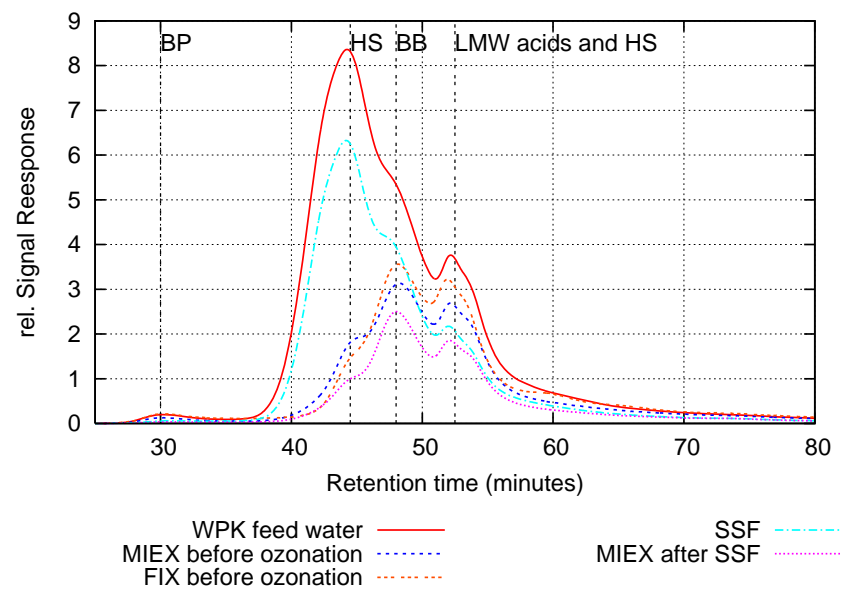

(a) OCD chromatograms

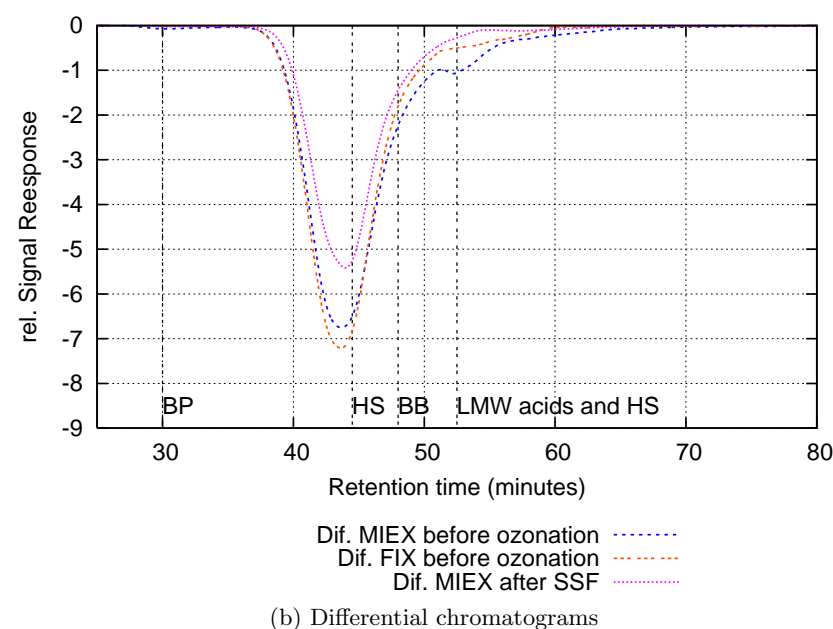

Figure 2. LC-OCD (differential) chromatograms of the different water qualities.

period between these two values, which made it impossible to calculate a BFR for the biofilm monitor positioned after MIEX $^{\circledR}$. The tube settlers and the magnetic capture device of the MIEX ${ }^{\circledR}$ pilot plant did not remove all spent resin and polluted the biofilm monitor. The MIEX ${ }^{\circledR}$ pilot plant caused an average increase in turbidity from 0.1 NTU to 1.5 NTU. This increase in turbidity after MIEX ${ }^{\circledR}$ treatment was also noticed by Singer and Bilyk (2002); Cornelissen et al. (2010) found an increase in ATP content after FIX. The higher ATP values after MIEX ${ }^{\circledR}$ treatment were probably caused by ATP on the resin that polluted the biofilm monitor. This problem can be solved by adding an extra (magnetite) filter. This filter should remove the resin before the water is transported to the consumers. The BFR of the finished water of the FIX-lane was $2.0 \mathrm{pg} \mathrm{ATP} \mathrm{cm}^{-2}$ day $^{-1}$ (Grefte et al., 2011), which is an improvement compared to the existing values of

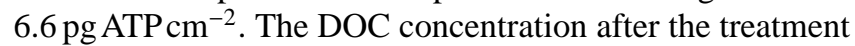
lane was lowered from 4.3 to $2.3 \mathrm{mgCL}^{-1}$, due to FIX pretreatment. MIEX after SSF decreased the DOC concentration
Table 4. Regeneration and waste characteristics of three possible positions for the IEX plant in the treatment lane.

\begin{tabular}{lccc}
\hline & $\begin{array}{c}\text { Before } \\
\text { coagulation }\end{array}$ & $\begin{array}{c}\text { Before } \\
\text { ozonation }\end{array}$ & $\begin{array}{c}\text { After } \\
\text { SSF }\end{array}$ \\
\hline DOC removal rate & $61 \%$ & $62 \%$ & $67 \%$ \\
Regeneration after (BV) & 11100 & 10500 & 6800 \\
Regeneration after (Days) & 18.9 & 17.9 & 11.6 \\
Regenerations per year & 424 & 448 & 692 \\
Brine per year $\left(\mathrm{m}^{3}\right)$ & 6868 & 7257 & 11210 \\
Rinse water per year $\left(\mathrm{m}^{3}\right)$ & 9158 & 9677 & 14947 \\
Salt per year $(\mathrm{kg})$ & 686880 & 725760 & 1121040 \\
DOC $\left({\left.\mathrm{kg} \mathrm{C} \mathrm{yr}^{-1}\right)}^{165000}\right.$ & 114000 & 60000 \\
\hline
\end{tabular}

from 4.3 to $1.8 \mathrm{mgCL}^{-1}$. Thus the biological stability of the water after the treatment lane, expressed as DOC, AOC and BFR, improved by extension of the treatment train with FIX. MIEX improved biological stability expressed as DOC and AOC, but results for BFR were obscured by spent resin. Unfortunately the values of DOC and $\mathrm{AOC}$ were not below the aimed concentrations of $10 \mu \mathrm{gCL} \mathrm{CL}^{-1}$ for $\mathrm{AOC}$ and $1 \mathrm{mgCL}^{-1}$ for DOC, but the pilot plant (specifically the BAC filters) was not as effective in DOC removal as is the full-scale treatment plant (Grefte et al., 2011), so it is expected that the aimed values will be reached when implementing FIX in the full-scale treatment.

\subsection{IEX cost comparison}

Three positions were selected for NOM removal by IEX: (1) before coagulation, (2) before ozonation and (3) as a polishing step after SSF. IEX added before coagulation is expected to remove DOC from 9.0 to $3.5 \mathrm{mgCL}^{-1}$ (Table 1), which is a removal rate of $61 \%$. From Fig. 1 the run time of every column can be determined; for a removal rate of $61 \%$ the run time will be approximately $11100 \mathrm{BV}$. The design flow through every column is $220 \mathrm{~m}^{3} \mathrm{~h}^{-1}$, which means that every column should be regenerated every 19 days. When IEX is positioned before coagulation, the DOC removal is $5.5 \mathrm{~g} \mathrm{Cm}^{-3}$. From 30 Million $\mathrm{m}^{3}$ treated water $165000 \mathrm{~kg} \mathrm{C}$ needs to be discharged. In Table 4 the regeneration and waste characteristics of the three possible positions of the IEX plant are given. The regeneration frequencies of the three positions were calculated based on the expected removal of DOC given in Table 1, combined with the relation between removal rate and run time given in Fig. 1. It is shown that because of the higher regeneration frequency more brine and rinse water will be produced and more salt will be used when IEX is placed after SSF, than when IEX is placed before coagulation or before ozonation. The amount of DOC in the brine is very high for water treated by IEX before coagulation because of the high required (absolute) DOC removal at this position. In Table 5 the estimated operational and fixed costs are given. The highest IEX costs are $0.0656 € \mathrm{~m}^{-3}$ when IEX is placed 


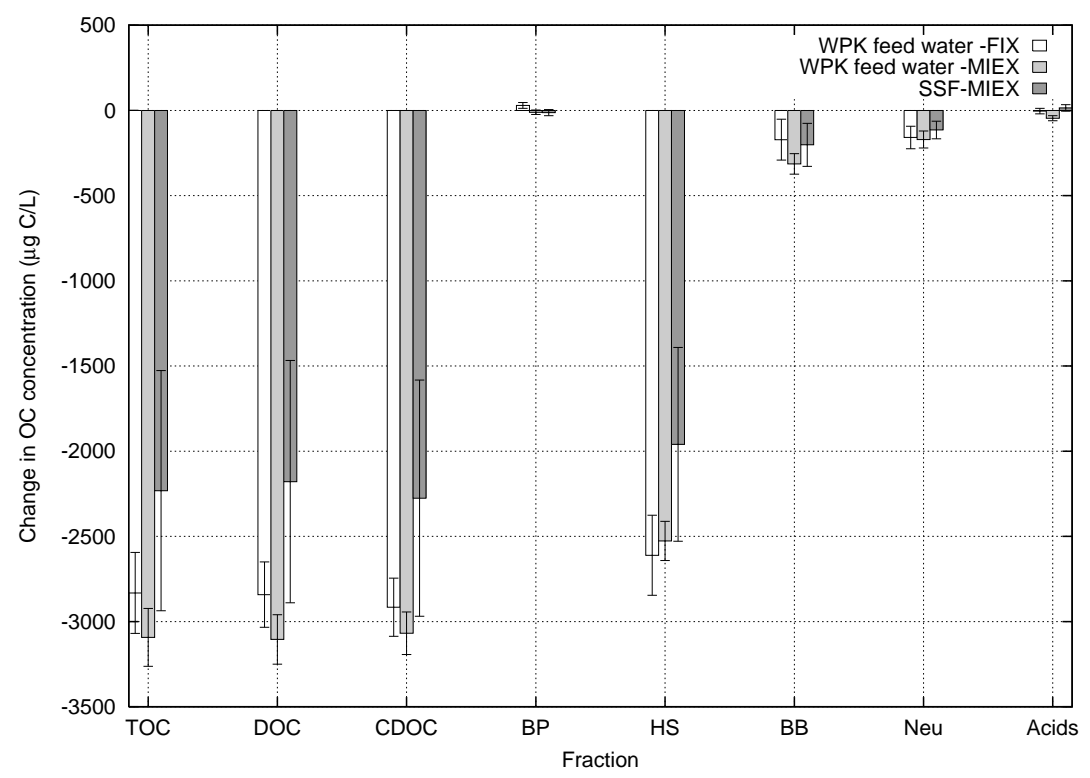

(a) Removal

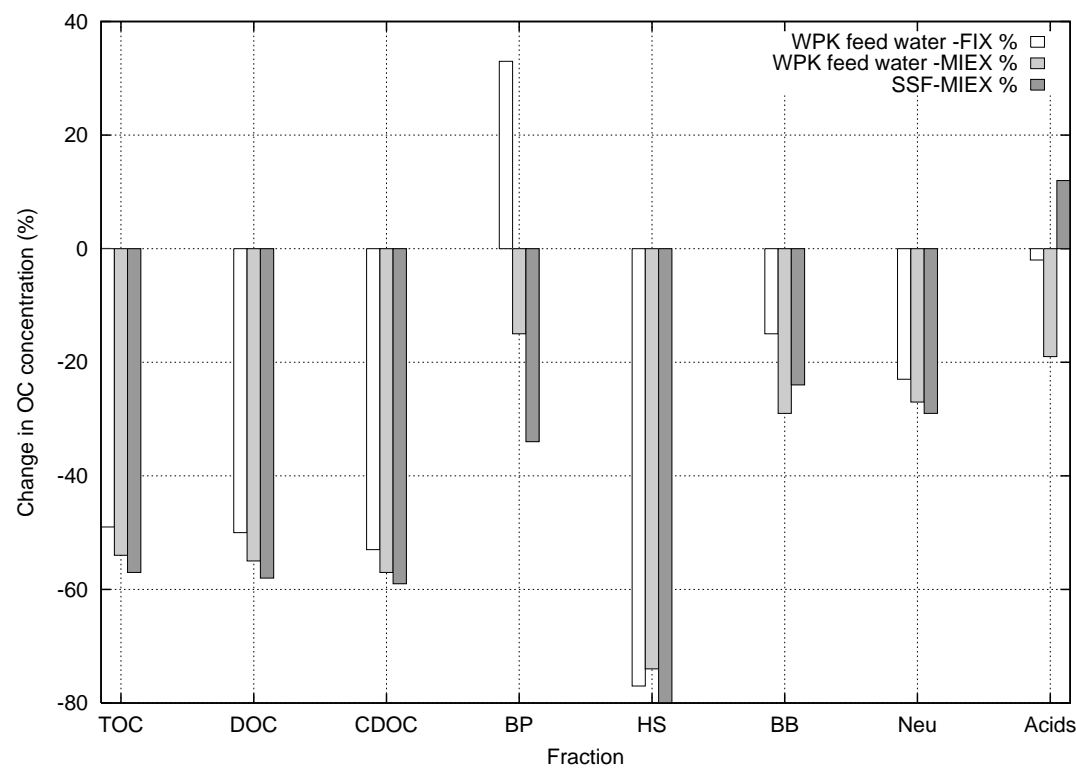

(b) Removal rate

Figure 3. Change in NOM fraction concentrations in the different water types by MIEX ${ }^{\circledR}$ and FIX.

before coagulation. The cheapest option is to place IEX before ozonation, but the difference in costs between these two positions is only $6 \%$. The costs for waste are $34 \%$ of the total costs. Brine treatment by NF, which means $90 \%$ waste reduction (Schippers et al., 2004), will reduce the price.

\subsection{Expected costs savings on subsequent treatment processes}

The addition of an IEX installation in the treatment lane will influence subsequent treatment processes in operation and quality as well as costs. Removing NOM before coagulation will save coagulant, even when the main purpose of coagulation is turbidity removal (Singer and Bilyk, 2002). Currently, coagulation removes $1.9 \mathrm{mgCL}^{-1}$, when IEX is incorporated before coagulation DOC removal is only $0.75 \mathrm{mg} \mathrm{CL}^{-1}$. DOC removal will be lowered by $60 \%$, assuming a linear dependency of the coagulant dose and sludge production on DOC, these can be reduced by $60 \%$ as well (White et al., 1997). This will save $0.0037 € \mathrm{~m}^{-3}$ (Barrios et al., 2008). (The purpose of coagulation at Loenderveen is also removal 


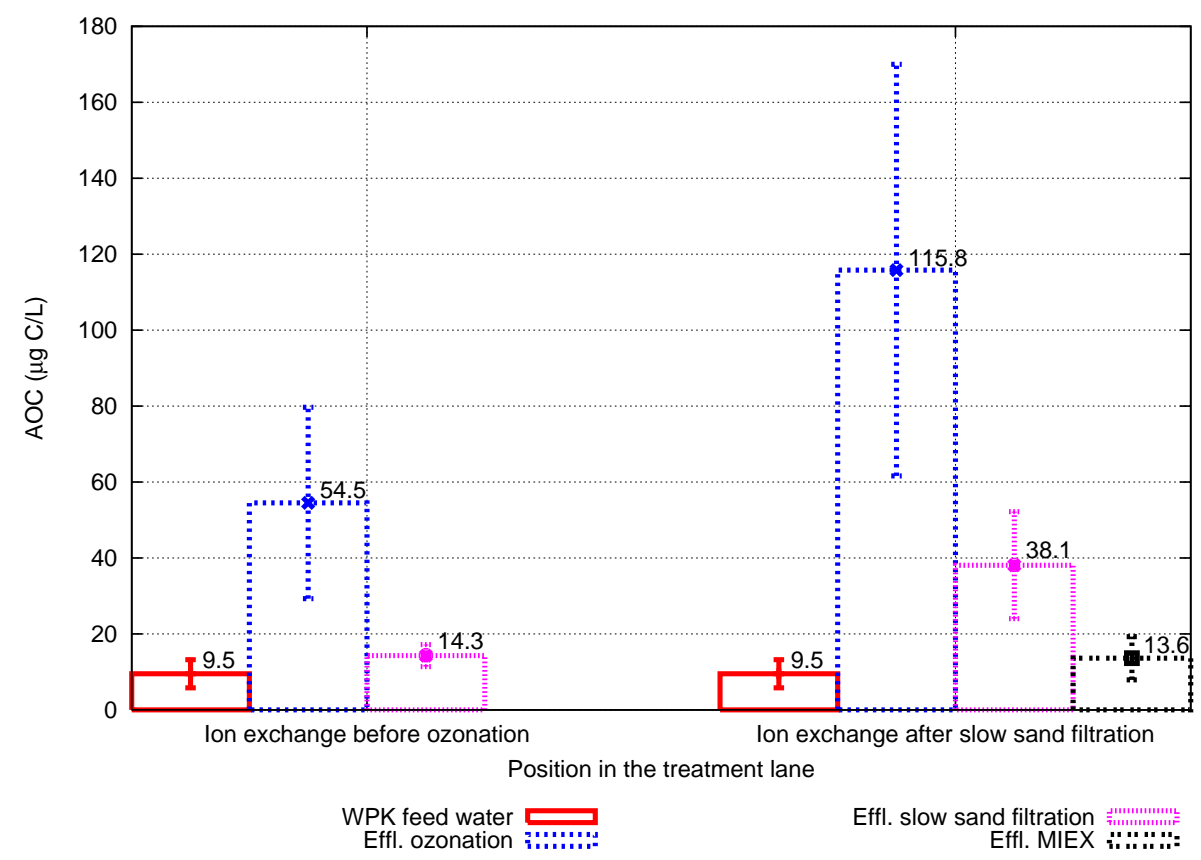

Figure 4. AOC concentrations in the treatment lanes when FIX was positioned before ozonation or MIEX was positioned after SSF.

Table 5. Total costs of IEX at three different positions in the treatment lane.

\begin{tabular}{lrrr}
\hline Costs $\left(€ \mathrm{yr}^{-1}\right)$ & $\begin{array}{r}\text { Before } \\
\text { coagulation }\end{array}$ & $\begin{array}{r}\text { Before } \\
\text { ozonation }\end{array}$ & $\begin{array}{r}\text { After } \\
\text { SSF }\end{array}$ \\
\hline Waste transport & 224364 & 237076 & 366198 \\
Waste discharge & 451642 & 312044 & 164234 \\
Salt & 68688 & 72576 & 112104 \\
Fixed costs & 1224000 & 1224000 & 1224000 \\
\hline Total & 1968694 & 1845696 & 1866536 \\
$€ \mathrm{~m}^{-3}$ & 0.0656 & 0.0615 & 0.0622 \\
\hline
\end{tabular}

of phosphate for preventing eutrophication of the lake reservoir. The effect of NOM on phosphate removal is unknown, therefore the reduction in coagulant dose at Loenderveen could be less than $60 \%$.)

When a linear relation between ozone dosage per DOC concentration and disinfection capacity is adopted, the ozone dosage can be reduced from 2.0 to $0.75 \mathrm{mgL}^{-1}$. This will save $0.0040 € \mathrm{~m}^{-3}$ (Barrios et al., 2008).

Currently, the contact time in the BAC filters is $52 \mathrm{~min}$, approximately 15 out of 26 filters are regenerated per year. The run time of each filter is approximately $1.7 \mathrm{yr}$. When IEX is incorporated in the treatment lane before BAC, the DOC removal can be reduced by $66 \%$. Assuming an increase in runtime of $66 \%$, only 9 columns need to be regenerated per year, resulting in a saving of $0.0089 € \mathrm{~m}^{-3}$ (Barrios et al., 2008).
Comparing the net costs (Table 6) shows that IEX before coagulation and IEX before ozonation are the most cost effective options because of the savings on coagulation, ozonation and BAC. In this specific case study IEX before ozonation will be the most cost effective option, because removal of phosphate must be sufficient, the reduction in coagulant and thus the cost savings on coagulation will be less than calculated. IEX positioned after SSF does not influence other treatment steps and therefore the net costs are the highest.

The customer of Waternet pays $1.70 € \mathrm{~m}^{-3}$ (VEWIN, 2011) for their tap water. The total production costs of drinking water at Loenderveen and Weesperkarspel treatment plant are $0.1592 € \mathrm{~m}^{-3}$ (Barrios et al., 2008). The production costs of IEX consists of replacement of the Lewatit VP OC 1071 resin $(220000 € y r)$, costs for energy $(81000 € y r)$, waste transport $(237076 € y$ r), waste discharge $(312044 € \mathrm{yr})$ and costs for salt $(72576 € \mathrm{yr})$ (Tables 3 and 5), this makes the total production costs $0.0308 € \mathrm{~m}^{-3}$ for the position before ozonation, without savings on subsequent treatment steps. The increase in production costs is $19 \%$. The total costs for placing IEX before ozonation are $0.0486 € \mathrm{~m}^{-3}$ (see Table 6), the water price for the consumer will increase by $2.9 \%$

\subsection{Environmental impact}

Pellet softening is the main contributor to the environmental impact at Waternet (Barrios et al., 2008) due to the use of sodium hydroxide $(\mathrm{NaOH})$. The softening process will not be improved by IEX. The second largest 
Table 6. Expected savings of downstream processes because of IEX and the calculated net costs.

\begin{tabular}{lrrr}
\hline Costs $\left(€ \mathrm{~m}^{-3}\right)$ & $\begin{array}{r}\text { Before } \\
\text { coagulation }\end{array}$ & $\begin{array}{r}\text { Before } \\
\text { ozonation }\end{array}$ & $\begin{array}{r}\text { After } \\
\text { SSF }\end{array}$ \\
\hline Costs & 0.0656 & 0.0615 & 0.0622 \\
\hline Savings & & & \\
Coagulation & 0.0037 & - & - \\
Ozonation & 0.0040 & 0.0040 & - \\
BAC & 0.0089 & 0.0089 & - \\
\hline Net costs & 0.0490 & 0.0486 & 0.0622 \\
\hline
\end{tabular}

contributor to the environmental impact is coagulation $\left(2.01 \times 10^{-3}\right.$ Eco Points $\left.\mathrm{m}^{-3}\right)$ because of the use of ferric chloride $(71.3 \%)$ (Barrios et al., 2008). By incorporating IEX before coagulation, the coagulant dose can be reduced by $60 \%$, which decreases the environmental impact of coagulation to $1.15 \times 10^{-3}$ Eco Points $\mathrm{m}^{-3}$. Furthermore, regeneration of $\mathrm{BAC}$ determines for a large part $(59.5 \%$ of $1.17 \times 10^{-3}$ Eco Points $^{-3}$ ) the height of the environmental impact for BAC (Barrios et al., 2008). The regeneration of BAC columns will be decreased by prior NOM removal by IEX from 15 columns to 9 columns per year, which is a decrease of $40 \%$. The environmental impact of BAC will decrease to $0.89 \times 10^{-3}$ Eco Points $\mathrm{m}^{-3}$. Although the reduction of ozone dosage influenced the costs, it will have a negligible effect on the environmental impact (Barrios et al., 2008). It is expected that the environmental impact of an IEX plant would be mainly determined by energy cost, in that way the environmental impact of an IEX treatment will be comparable with the low impact of rapid sand filtration. The environmental impact of rapid sand filtration consists for $80 \%$ of $\mathrm{NaOH}$ dose. The expected environmental impact of IEX will be $20 \%$ the environmental impact of rapid sand filtration, so the environmental impact of IEX will be $0.14 \times 10^{-3}$ Eco Points $^{-3}$ (Barrios et al., 2008). Extending the treatment lane with IEX before coagulation and ozonation will therefore decrease the (already low) environmental impact of the drinking water treatment. IEX positioned before coagulation will decrease the environmental impact from $8.6 \times 10^{-3}$ Eco Points $^{-3}$ to $7.6 \times 10^{-3}$ Eco Points $^{-3}$, the environmental impact for the treatment when IEX is po-

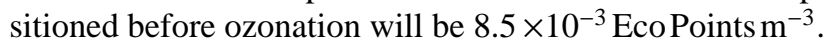

\section{Conclusions}

Different placement positions of IEX in the treatment lane (IEX positioned before coagulation, before ozonation or after slow sand filtration) and two IEX configurations (MIEX ${ }^{\circledR}$ and FIX) were compared on water quality as well as costs. For this purpose the pre-treatment plant at Loenderveen and production plant Weesperkarspel of Waternet were used as a case study.

Both, MIEX ${ }^{\circledR}$ and FIX were able to remove NOM (mainly the HS fraction) to a high extent, which improved the water quality. NOM removal can be done efficiently before ozonation and after slow sand filtration, because the position in the treatment lane did not influence the NOM removal percentage.

In this study, biologically stable water was defined in terms of AOC, BFR and DOC. By removing humic substances by FIX before ozonation less biodegradable NOM was formed than without FIX and the biological stability (AOC, BFR and DOC) of the drinking water was improved (Grefte et al., 2011). MIEX ${ }^{\circledR}$ positioned after slow sand filtration caused a decrease in DOC and AOC.

The operational costs were assumed to be directly dependent of the NOM removal rate and determined the difference between the IEX positions. The total costs for IEX for the three positions were approximately equal $\left(0.0631 € \mathrm{~m}^{-3}\right.$ on average, Table 6), however the savings on following treatment processes caused a cost reduction for the IEX positions before coagulation and before ozonation compared to IEX positioned after SSF. IEX positioned before ozonation was most cost effective and improved the biological stability of the treated water.

Acknowledgements. This study was part of a project about natural organic matter (NOM) in drinking water distribution networks. Subsidy for the NOM project was provided by Senter Novem. The project is a joint research project of KWR watercycle research institute, UNESCO-IHE, Delft University of Technology, the water supply Companies Vitens and Waternet, water cycle company for Amsterdam and surrounding areas. The MIEX ${ }^{\circledR}$ pilot plant was provided by Orica Watercare, the authors would like to acknowledge the dedicated support from Orica Watercare personnel.

Edited by: D. Knappe

\section{References}

Allpike, B., Heitz, A., Joll, C., Kagi, R., Abbt-Braun, G., Frimmel, F., Brinkmann, T., Her, N., and Amy, G.: Size exclusion chromatography to characterize DOC removal in drinking water treatment, Environ. Sci. Technol., 39, 2334-2342, 2005.

Baghoth, S. A., Dignum, M., Grefte, A., Kroesbergen, J., and Amy, G. L.: Characterization of NOM in a drinking water treatment process train with no disinfectant residual, Water Sci. Technol., 9, 379-386, 2009.

Barrios, R., Siebel, M., van der Helm, A., Bosklopper, K., and Gijzen, H.: Environmental and financial life cycle impact assessment of drinking water production at Waternet, J. Clean. Prod., 16, 471-476, 2008.

Bolto, B., Dixon, D., Eldridge, R., King, S., and Linge, K.: Removal of natural organic matter by ion exchange, Water Res., 36, 50575065, 2002. 
Boyer, T. H. and Singer, P. C.: Bench-scale testing of a magnetic ion exchange resin for removal of disinfection by-product precursors, Water Res., 39, 1265-1276, 2005.

Cornelissen, E., Moreau, N., Siegers, W., Abrahamse, A., Rietveld, L., Grefte, A., Dignum, M., Amy, G., and Wessels, L.: Selection of anionic exchange resins for removal of natural organic matter (NOM) fractions, Water Res., 42, 413-423, 2008.

Cornelissen, E., Beerendonk, E., Nederlof, M., van der Hoek, J., and Wessels, L.: Fluidized ion exchange (FIX) to control NOM fouling in ultrafiltration, Desalination, 236, 334-341, 2009.

Cornelissen, E., Chasseriaud, D., Siegers, W., Beerendonk, E., and van der Kooij, D.: Effect of anionic fluidized ion exchange (FIX) pre-treatment on nanofiltration (NF) membrane fouling, Water Res., 44, 3283-3293, 2010.

Croue, J.-P., Voilleau, D., Bodaire, C., and Legube, B.: Removal of hydrophobic and hydrophilic constituents by anion exchange resin, Water Sci. Technol., 40, 207-214, 1999.

DowChemicalCompany: Dow Water and Process Solutions - Correlation between $\mathrm{KMnO}_{4}$, COD, BOD, DOC and TOC, https: //dow-answer.custhelp.com/app/answers/detail/a_id/4219/ / dow-water-and-process-solutions-correlation-between-kmno4, -cod,-bod,-doc-and, 2011.

Drikas, M., Morran, J., Pelekani, C., Hepplewhite, C., and Bursill, D.: Removal of natural organic matter - a fresh approach, Water Sci. Technol., 2, 71-79, 2002.

Eaton, A. D., Clesceri, L. S., Rice, E. W., Greenberg, A. E., and Franson, M. A. H.: Standard methods for the examination of water and wastewater 2005, 21 Edn., American Public Health Association and American Water Works Association and Water Environment Federation, Baltimore, USA, 2005.

Edzwald, J. K., Becker, W. C., and Wattier, K. L.: Surrogate Parameters for Monitoring Organic Matter and THM Precursors, J. AWWA, 77, 122-132, 1985.

Galjaard, G., Martijn, B., Koreman, E., Bogosh, M., and Malley, J.: Performance evaluation SIX-Ceramac in comparison with conventional pre-treatment techniques for Surface Water Treatment, Water Practice \& Technology, 6, doi:10.2166/wpt.2011.0066, 2011.

Grefte, A., Dignum, M., Baghoth, S., Cornelissen, E., and Rietveld, L.: Improving the biological stability of drinking water by ion exchange, Water Sci. Technol., 11, 107-112, 2011.

Huber, S. and Frimmel, F.: Size-exclusion chromatography with organic carbon detection (LC-OCD): a fast and reliable method for the characterization of hydrophilic organic matter in natural waters, Vom Wasser, 86, 277-290, 1996.

Huber, S. A.: Origin and Behaviour of Non-Ionic Natural Organic Matter (NOM) in Boiler Feed Water, in: International Water Conference, Orlando, Florida, 2005.

Huber, S. A., Balz, A., Abert, M., and Pronk, W.: Characterisation of aquatic humic and non-humic matter with size-exclusion chromatography - organic carbon detection - organic nitrogen detection (LC-OCD-OND), Water Res., 45, 879-885, 2011.
Humbert, H., Gallard, H., Suty, H., and Croue, J.-P.: Performance of selected anion exchange resins for the treatment of a high DOC content surface water, Water Res., 39, 1699-1708, 2005.

Kabsch-Korbutowicz, M., Wisniewski, J., Lakomska, S., and Urbanowska, A.: Application of UF, NF and ED in natural organic matter removal from ion-exchange spent regenerant brine, Desalination, 280, 428-431, 2011.

Korshin, G., Benjamin, M., and Li, C.-W.: Use of differential spectroscopy to evaluate the structure and reactivity of humics, Water Sci. Technol., 40, 9-16, 1999.

Lewatit: Product information Lewatit VP OC 1071 http://www. lewatit.com, n.d.

OricaWatercare: MIEX Treatment Systems-High Rate Configuration, http://www.miexresin.com/files/High\%20Rate\% 20Brochure\%20V0307.pdf, n.d.

Schippers, D., Kooi, M., Sjoerdsma, P., and de Bruijn, F.: Colour removal by ion exchange and reuse of regenerant by means of nanofiltration, Water Sci. Technol., 4, 57-64, 2004.

Singer, P. C. and Bilyk, K.: Enhanced coagulation using a magnetic ion exchange resin, Water Res., 36, 4009-4022, 2002.

van der Helm, A. W. C., Grefte, A., Baars, E. T., Rietveld, L. C., van Dijk, J. C., and Amy, G. L.: Effects of natural organic matter (NOM) character and removal on ozonation for maximizing disinfection with minimum bromate and AOC formation, J. Water Supply Res. T., 58, 373-385, 2009.

van der Kooij, D.: Assimilable organic carbon as an indicator of bacterial regrowth, J. Am. Water Works Ass., 84, 57-65, 1992.

van der Kooij, D. and Hijnen, W.: Substrate utilisation by an oxalate-consuming Spirillum species in relation to its growth in ozonated water, Appl. Environ. Microb., 47, 551-559, 1984.

van der Kooij, D., Visser, A., and Hijnen, W.: Determining the concentration of easily assimilable organic carbon in drinking water, J. Am. Water Works Ass., 74, 540-545, 1982.

van der Kooij, D., Veenendaal, H. R., Baars-Loristand, C., van der Klift, H. W., and Drost, Y. C.: Biofilm formation on surfaces of glass and Teflon exposed to treated water, Water Res., 29, 16551662, 1995.

van der Kooij, D., van Lieverloo, J., Schellart, J., and Hiemstra, P.: Maintaining quality without a disinfectant residual, J. Am. Water Works Ass., 91, 55-64, 1999.

van der Kooij, D., Vrouwenvelder, J. S., and Veenendaal, H. R.: Elucidation and control of biofilm formation processes in water treatment and distribution using the unified biofilm approach, Water Sci. Technol., 47, 83-90, 2003.

van Lier, J.: Lecture Notes Wastewater Treatment, Sanitary Engineering (CT3420), TU Delft, 2011.

VEWIN: Tarievenoverzicht drinkwater per 1 januari 2012, http://www.vewin.nl/SiteCollectionDocuments/Publicaties/ tarievenoverzicht_2012.pdf, 2012.

White, M., Thompson, J., Harrington, G., and Singer, P.: Evaluating criteria for enhanced coagulation compliance, J. Am. Water Works Ass., 89, 64-77, 1997. 